\title{
PERANCANGAN INFOGRAFIS STATIS TENTANG GENERALIZED ANXIETY DISORDER (GAD)
}

\author{
Alfian$^{1)}$, Abdul Aziz Nurafriansyah ${ }^{2)}$ \\ Program Studi Desain Komunikasi Visual \\ Fakultas Bahasa dan Seni Universitas Indraprasta PGRI \\ Jl. Nangka 58 C Tanjung Barat, Jakarta Selatan, 12530, Indonesia \\ Muhamadalfian42@gmail.com
}

\begin{abstract}
Abstrak
Kecemasan adalah peraasan takut yang muncul ketika seorang individu merasa dirinya teranacam oleh sesuatu dan dapat menimbulkan bahaya pada diri mereka yang disebabkan oleh situasi tertentu. Pada normalnya, kecemasan dapat membantu seseorang untuk lebih waspada agar tidak mengalami masalah atau hal yang dapat merugikan dirinya, namun dalam porsi yang berlebihan kecemasan dapat menimbulkan ganggauan yang sangat serius dan dapat mengganggu kinerja dan fungsi seseorang dalam kehidupannya. Salah satu gangguan yang paling sering muncul adalah Genaralized Anxiety Disorder (GAD) atau Gangguan Cemas Menyeluruh. Gangguan cemas ini bisa berlangsung sangat lama bahkan seumur hidup. Metode yang digunakan dalam membuat perancangan ini adalah metode kualitatif menggunakan data sekunder, data sekunder adalah data yang diperoleh dengan mencari dari berbagai macam referensi tertulis, baik dari jurnal tertulis maupun artikel daring. Tujuan dari perancangan infografis statis ini adalah membantu masyarakat memahami apa itu gangguan kecemasan umum dan mengetahui cara menanganinnya dan mengurangi gejalanya.
\end{abstract}

Kata Kunci: Kecemasan, GAD, Gangguan cemas, Infografis statis, Kualitatif

\begin{abstract}
Anxiety is a feeling of fear that arises when an individual feels himself assorted by something and can cause danger to themselves caused by certain situations. Normally, anxiety can help someone to be more vigilant so as not to experience problems or things that can harm him but in portions excessive anxiety can cause very serious disorders and can interfere with the performance and function of a person in his life. One of the most common disorders that appear is Genaralized Anxiety Disorder (GAD) or overall anxiety disorders. It can last a very long time or even for the lifetime. The method used in making this design is a qualitative method using secondary data, secondary data is data obtained by searching from a variety of written references both from written journals and online articles. The purpose of designing static infographics is to help people understand what generalized anxiety disorder is and know how to manage it and reduce symptoms.
\end{abstract}

Keywords: Anxiety, GAD, Anxiety disorders, Static infographics, Qualitative

Correspondence author: Alfian, Muhamadalfian42@gmail.com, Jakarta, and Indonesia

This work is licensed under a $C C-B Y-N C$ 


\section{PENDAHULUAN}

Setiap harinya manusia dihadapkan dengan berbagai kondisi ataupun kejadian yang dapat menimbulkan rasa kecemasan. Contohnya seperti presentasi di depan orang banyak, terlambat datang ujian, deadline tugas atau pekerjaan, ujian mendadak, dan sebagian lainnya. Kecemasan merupakan suatu bentuk reaksi manusia yang wajar terjadi dan dapat dialami oleh siapapun, sebagai respon terhadap situasi atau hal yang dapat mengancam dan membahayakan bagi dirinya. Namun jika kecemasan tersebut sudah melebihi ambang batas serta berlebihan tidak sesuai dengan proporsi ancamannya, maka bisa mengarah ke gangguan yang dapat menghabat fungsi seseorang dalam kehidupannya.

Kaplan, Sadock dan Grebb (dalam Fausiah \& Widury, 2007) menyatakan bahwa kecemasan adalah respon terhadap situasi tertentu yang mengancam. Itu merupakan hal yang normal terjadi menyertai perkembangan, perubahan, pengalaman baru atau yang belum pernah dilakukan, serta dalam menemukan identitas diri dan arti hidup. Dalam keadaan normal, kecemasan dapat membantu individu dalam menentukan pilihan untuk mencegah bahaya dan untuk memperkecil kemungkinan bahaya tersebut akan terjadi. Kecemasan dalam taraf tertentu dapat mendoroang meningkatnya performa dan produktivitas. Contohnya adalah seorang mahasiswa yang cemas mendapat nilai buruk dalam ujian yang akan dia hadapi sehingga membuat mahasiswa tersebut belajar giat untuk mempersiapkan diri untuk ujian yang akan dihadapi.

Rasa khawatir yang dirsakan berlebihan bisanya didiagnosis dengan Generalized Anxiety Disorder (GAD) mungkin kita sering mersa cemas tentang kehidupan atau pekerjaan yang kita jalani, namun penderita GAD memiliki rasa kekhawatiran yang berlebih dan tidak realistis tentang banyak hal. Mereka cenderung mengkhawatirkan banyak hal dalam kehidupan sehari-hari, mereka tidak bisa berhenti mengkhawatirkan seperti kerja, kesehatan, uang atau keamanan diri mereka. Perbedaan utama antara GAD dan gangguan kecemasan lainnya dalah orang dengan gangguan kecemasan lainnya biasanya hanya berfokus terhadap satu hal yang spesifik, sedangkan penderita GAD khawatir akan banyak hal.

Meningkatnya jumlah pengidap gangguan mental setiap tahunnya membuktikan bahwa banyaknya individu yang belum mengetahui bagaimana menjaga kesehatan mental mereka sehingga menyebabkan banyak dari mereka mengetahui gangguan mental yang mereka alami sudah lama mereka idap, untuk itu perlu adanya media penyampaian informasi kepada khalayak luas agar dapat memberikan informasi penting untuk memahami batasan-batasan yang jelas kapan kecemesan yang dialami dikatakan sebagai gangguan, apa saja gejala yang muncul, serta upaya penanganan apa yang dapat diberikan untuk mengatasi gangguan kecemasan.

Tujuan dari artikel ini adalah membantu masyarakat untuk lebih mengenal penyakit gangguan kecemasan yang banyak pengidapnya namun banyak yang tidak menyadarinya karena tidak mengetahui informasi tentang gangguan kecemasan, oleh karena itu peneliti membuat solusi dari masalahn ini dengan membuat infografis stastis tentang gangguan kecemasan umum dengan menggunakan gaya desain terkini yaitu flat design agar dapat dengan mudah dimengerti dan diapahami oleh banyak orang, poster yang peneliti buat akan ditempatkan di tempat-tempat yang memiliki tingkat strees yang tinggi seperti perkantoran yang sibuk area-area berkumpulnya masa, sekolah.

\section{METODE PENELITIAN}

Metode penelitian dapat diartikan sebagai seluruh nilai, asumsi-asumsi, etika serta norma yang menjadi aturan-aturan standar yang dapat digunakan dalam menafsirkan data penelitian yang ada, termasuk dapat digunakan untuk menilai kualitas hasil penelitian. Pengumpulan data yang dilakukan menggunakan sumber data sekunder. Data sekunder adalah data-data yang diperoleh dari buku-buku, majalah, dan koran yang memberitakan tentang gangguan kecemasan umum. Peneliti mengumpulkan data dari berbagai sumber yang dapat dipertanggungjawabkan kredibilitasnya, memiliki data faktual, sehingga dapat mengurangi resiko kesalahan penulisan. Penelitian kualitatif adalah proses untuk mencari sebuah makna dari masalah sosial atau kemanusiaan yang sesuai dengan metodologi yang berbeda. Peneliti menyusun sebuah konsep 
yang kompleks, menganalisa sebuah artikel atau data dan menyusun hasil penelitian sesuai fakta dilapangan. Pengumpulan data dilakukan dengan teknik studi pustaka. Studi pustaka adalah sebuah kegiatan pengumpumpulan data dengan melakukan analisis yang diperoleh dari berbagai buku, literatur, catatan, serta jurnal yang berkaitan dengan topik yang diambil (Nazir:1998)

\section{HASIL DAN PEMBAHASAN}

Kaplan, Sadock, dan Grebb (dalam Fausiah \& Widury, 2007) menyatakan bahwa kecemasan adalah respon terhadap situasi tertentu yang mengancam, dan merupakan hal yang normal terjadi menyertai perkembangan, perubahan pengalaman baru atau yang belum pernah dilakukan, serta dalam menemukan identitas diri dan arti hidup. Dalam porsi yang tepat kecemasan dapat membantu sesorang untuk bersiaga mengambil langkah-langkah untuk mencegah atau memperkecil resiko dari ancaman tersebut. Kecemasan dalam porsi yang tepat dapat membantu seseorang meningkatkan performa dan produktivitas, contohnya mahasiswa yang akan menghadapai ujian akhir dan dia cemas tidak mendapat nilai yang bagus, sehingga dia belajar lebih giat lagi untuk mempersiapkan ujian akhir yang akan dia hadapi. Namun, jika kecemasan yang dihadapi mahasiswa ini memiliki porsi yang berlebih dan akhirnya malah menjadi gangguan karena tidak dapat berfokus pada tujuan sehingga menjadi ganguuan.

Salah satu gangguan kecemasayan yang banyak terjadi di kalangan masyarakat adalah GAD (generalized anxiety disorder) yaitu suatu gangguan kecemasan yang ditandai dengan perasaan cemas yang umum dan bahwa sesuatu yang buruk akan terjadi dan keadaan peningkatan keterangsangan tubuh. GAD ditandai dengan kecemasan yang persisten yang tidak dipicu oleh suatu objek, situasi atau aktivitas yang spesifik. GAD merupakan suatu gangguan yang stabil, muncul pada pertengahan remaja sampai pertengahan umur dua puluhan tahun dan kemudian berlangsung sepanjang hidup (Rapee dalam Nevid, dkk, 2005). GAD muncul pada usia remaja dan banyak tidak disadari oleh banyak orang, mereka hanya menganggap sakit fisik biasa dan memperiksakan diri ke dokter namun tidak menemukan gejala sakit yang mereka alami dan tidak menyadari penyakit sebenarnya yang mereka alami.

Tidak ada penyebab tunggal dari GAD, tapi para peneliti telah mengidentifikasi beberapa faktor resiko. Faktor-faktor ini berbeda untuk setiap individu:

1. Faktor biologis: keturunan, ketidakseimbangan kimia zat pengontrol fungsi otak, kesehatan fisik yang buruk

2. Faktor psikologis: orang yang mudah cemas, merasa tidak aman, pesimis, dan pasif

3. Faktor lingkungan: pengalaman negatif di masa kecil dan peristiwa stres lainnya dalam hidup seperti pergantian pekerjaan, masalah hubungan, dan sebagainya.

Sebagian besar penderita GAD cenderung memiliki kepribadian cemas, sebagian dari mereka tidak bisa dengan tepat mengingat kapan gangguan ini pertamakali muncul atau dirasakan. Bentuk gangguan dari waktu ke waktu berhubungan dengan pengalaman stres dalam hidup. Secara umum, semakin lama seseorang menderita GAD, semakin lama waktu yang diperlukan untuk penyembuhan. Selain itu, peluang mereka menderita depresi atau gangguan kecemasan lainnya juga lebih tinggi daripada populasi umum.

Pedoman diagnostik untuk gangguan kecemasan menyeluruh menurut PPDGJ-III (F41.1) (Maslim, 2013)

1. Penderita harus menunjukkan anxietas sebagai gejala primer yang berlangsung hampir setiap hari untuk beberapa minggu sampai beberapa bulan, yang tidak terbatas atau hanya menonjol pada keadaan situasi khusus tertentu saja (sifatnya free floating atau mengambang).

2. Gejala-gejala tersebut biasanya mencakup unsur-unsur berikut:

a. Kecemasan (khawatir akan nasib buruk, merasa seperti di ujung tanduk, sulit konsentrasi, dsb).

b. Ketegangan motorik (gelisah, sakit kepala, gemetaran, tidak dapat santai).

c. Over-aktivitas otonomi (kepala terasa ringan, berkeringat, jantung berdebar-debar, sesak napas, keluhan lambung, pusing kepala, mulut kering, dsb). 
3. Pada anak-anak sering terlihat adanya kebutuhan berlebihan untuk ditenangkan (reassurance) serta keluhan-keluhan somatik berulang yang menonjol.

4. Adanya gejala-gejala lain yang sifatnya sementara (untuk beberapa hari), khususnya depresi, tidak membatalkan diagnosis utama gangguan kecemasan menyeluruh, selama hal tersebut tidak memenuhi kriteria lengkap dari episode depresi (F32), gankap dari episodedepresi (F32), gangguan anxietas fobik (F40), gangguan panik (F41.0), gangguan obsesif-kompulsif (F42).

Penelitian ini menghasilkan sebuah perancangan untuk memecah solusi dengan cara yang efektif, yaitu membuat sebuah poster himbauan atau informasi yang bisa bermanfaat bagi masyarakat. Peneliti memilih media poster karena mudah dibuat dan mudah diletakkan di tempat - tempat keramaian. Poster tersebut tidak memakan banyak ruang untuk menempatkannya. Poster juga lebih mudah dipublikasikan, disebar, dan diterima oleh masyarakat.

Teori yang digunakan dalam meneliti poster ini adalah teori semiotika. Semiotika adalah salah satu dari tujuh tradisi dalam teori komunikasi yang diungkapkan oleh Robert T. Craig. Sebagai sebuah teori komunikasi, teori semiotika komunikasi memandang komunikasi sebagai sebuah proses yang berdasar pada sistem tanda, termasuk di dalamnya adalah bahasa dan semua hal yang terkait dengan kode-kode nonverbal untuk berbagi makna yang melintasi kesenjangan yang terjadi antara sudut pandang subyektif. Secara umum, semiotika adalah ilmu tentang tanda. Terdapat berbagai macam pengertian tentang semiotika yang dirumuskan oleh para ahli semiotika, salah satunya adalah Roland Barthes, yang menyatakan bahwa semiologi adalah tujuan untuk mengambil berbagai sistem tanda seperti substansi dan batasan, gambar-gambar, berbagai macam gesture, berbagai suara musik, serta berbagai obyek, yang menyatu dalam system of significance. Menurut Roland Barthes, semiotika memiliki beberapa konsep inti, yaitu signification, denotation dan connotation, dan metalanguage atau myth (Yan dan Ming, 2014).

\section{Konsep Dasar Perancangan Infografis Generalized Anxiety Disorder}

\section{Analisis Khalayak}

Konsep yang digunakan untuk merancang infografis generalized anxiety disorder adalah untuk memberikan informasi bagi khalayak yang dituju oleh perancangan infografis ini. Berikut adalah penjelasan mengenai analisis khalayak yang dituju dari segi geografis, demografis, targetting serta positioning. Segmentasi secara geografis, masyarakat yang cocok menjadi target adalah daerah perkotaan karena tingkat stress di perkotaan lebih tinggi daripada di desa, namun tidak menutup kemungkinan masyarakat di daerah pedesaan menjadi target.

Segmentasi secara demografis, masyarakat yang cocok dengan poster ini adalah semua jenis kelamin, terutama remaja dengan usia produktif, status sosial berada pada tingkat ekonomi semua kalanagan masyarakat, segmentasi secara psikografis, masyarakat yang cocok dengan segmentasi adalah masyarakat di perkotaan yang memimiliki kegiatan yang sibuk dan menimbulkan stress yang dapat menimbulkan gangguan kecemasan, sesuai dengan segmentasi yang peneliti buat, diharapkan poster ini dapat menarik perhatian masyarakat yang dituju.

\section{Konsep Verbal}

Headline: GENERALIZED ANXIETY DISORDER

Bodycopy: Sebagai individu kita harus mengetahui apa saja yang dapat menganggu kesehatan mental kita seperti gangguan kecemasan, kita harus mengenalai beberapa gejalanya seperti mudah marah, mudah tersinggung, meimikirkan hal yang tidak realistis yang dapat mengancam diri, berkeringat berlebihan. Kita harus dapat mengenali diri kita lebih baik, ada juga cara pencegahan agar tidak terjadi gangguan kecemasan umum seperti berpikir positif, berolahraga secara teratur membaca buku, menemukan hobi, ikut aktivitas sosial ada juga kriteria 


\section{Konsep Visual}

a. Ikon individu yang sedang cemas dengan memegang kepala menjadi gambaran seseorang yang terkena gangguan kecemasan, dikelilingi oleh berbagai kriteria yang menunjukan seseorang mengalami gangguan kecemasan umum. Hal tersebut diterapkan agar pembaca terfokus dengan krteria yang menjadikan seseorang mengalami gangguan kecemasan.
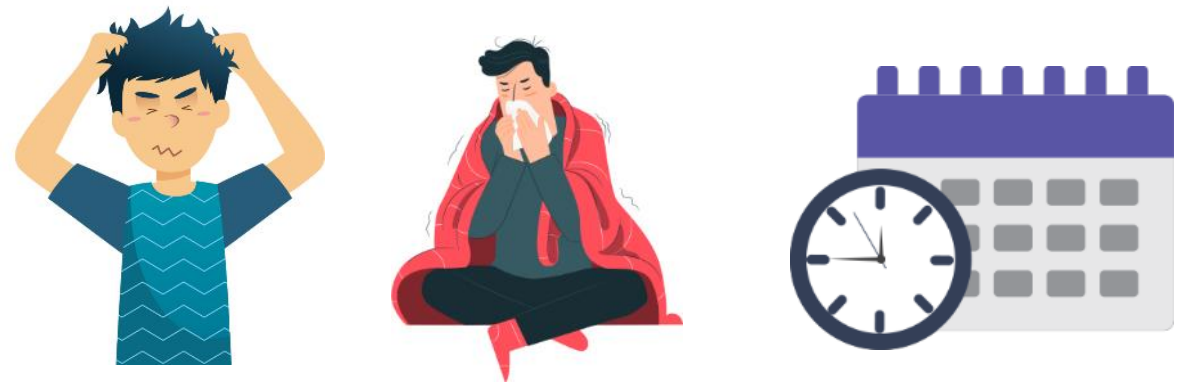

Gambar 1. Ikon

Sumber: Dokumentasi pribadi, 2020

b. Layout tata visual dari poster ini secara keseluruhan berbentuk persegi panjang, memanjang ke bawah. Di bagian atas poster terdapat penjelasan tentang apa itu gangguan kecemasan umum yang diletakan tepat di bawah headline. Di bagian tengah, terdapat ilustrasi dan serta teks yang menjelaskan ilustrasi tentang apa gejala dari gangguan kecemasan dan bagaimana cara mencegahnya.

c. Warna adalah faktor terpenting dalam komunikasi visual karena warna memberikan kesan psikologis, sugesti dan juga suasana bagi yang melihatnya (Soewignjo, 2013). Oleh karena itu, warna yang digunakan pada poster 'Generalized Anxiety Disorder' ini dibuat menggunakan warna belakang, kombinasi dari empat warna yaitu orange, cream, biru tua, dan muda. Pemilihan warna yang kontras dan cerah ini agar target dari poster tertarik dan betah berlama-lama untuk membacanya, sehinga informasi dari poster pun dapat dipahami oleh target audiens. Alasan pemilihan warna latar belakang biru pada headline adalah karena memiliki efek menenangkan pikiran dan meningkatkan konsentrasi, sehingga warna biru dapat digunakan untuk memfokuskan khalayak untuk membaca infografis statis ini. Sedangkan warna cream pada bagian tengah poster memberikan kesan lembut dan nyaman, sehingga membuat pembaca rileks saat membaca. Warna latar yang terakhir adalah oranye, memberi kesan hangat dan bersemangat, serta memberikan kesan petualangan, pada pemilihan huruf warna oranye juga sebagai penegasan text di dalam poster yang kami buat.

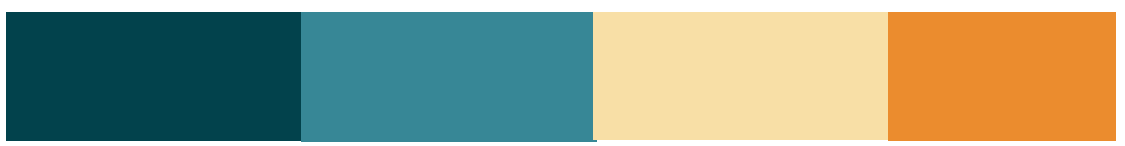

Gambar 2. Palet warna

Sumber: Dokumentasi pribadi, 2020

d. Tipografi Poster GENERALIZED ANXIETY DISORDER menggunakan tipografi yang berasal dari keluarga sans serif agar mudah dibaca dan pesan yang disampaikan mudah diterima oleh target dari poster yang telah dibuat. 


\section{Hasil Perancangan Infografis Statis General Anxiety Disorder}

Perencanaan penempatan media statis ini ialah pada tempat yang banyak dilihat orangorang dengan aktivitas padat yang menuntut kinerja yang baik, sehingga dapat menimbulkan stress yang berujung gangguan kecemasan, seperti perkantoran, sekolah SMA yang berisi remaja dengan tingkat pelaran yang padat. Peran orang-orang sekitar juga turut andil dalam menjaga kesehatan mental. Dengan mengetahui berbagai gejala yang terjadi, diharapkan dapat membantu individu yang terkena gangguan kecemasan. Selain itu, media ini nanti akan ditempatkan pada media sosial, seperti Facebook, Instagram, Website, Twitter, maupun media berbasis daring lainnya.

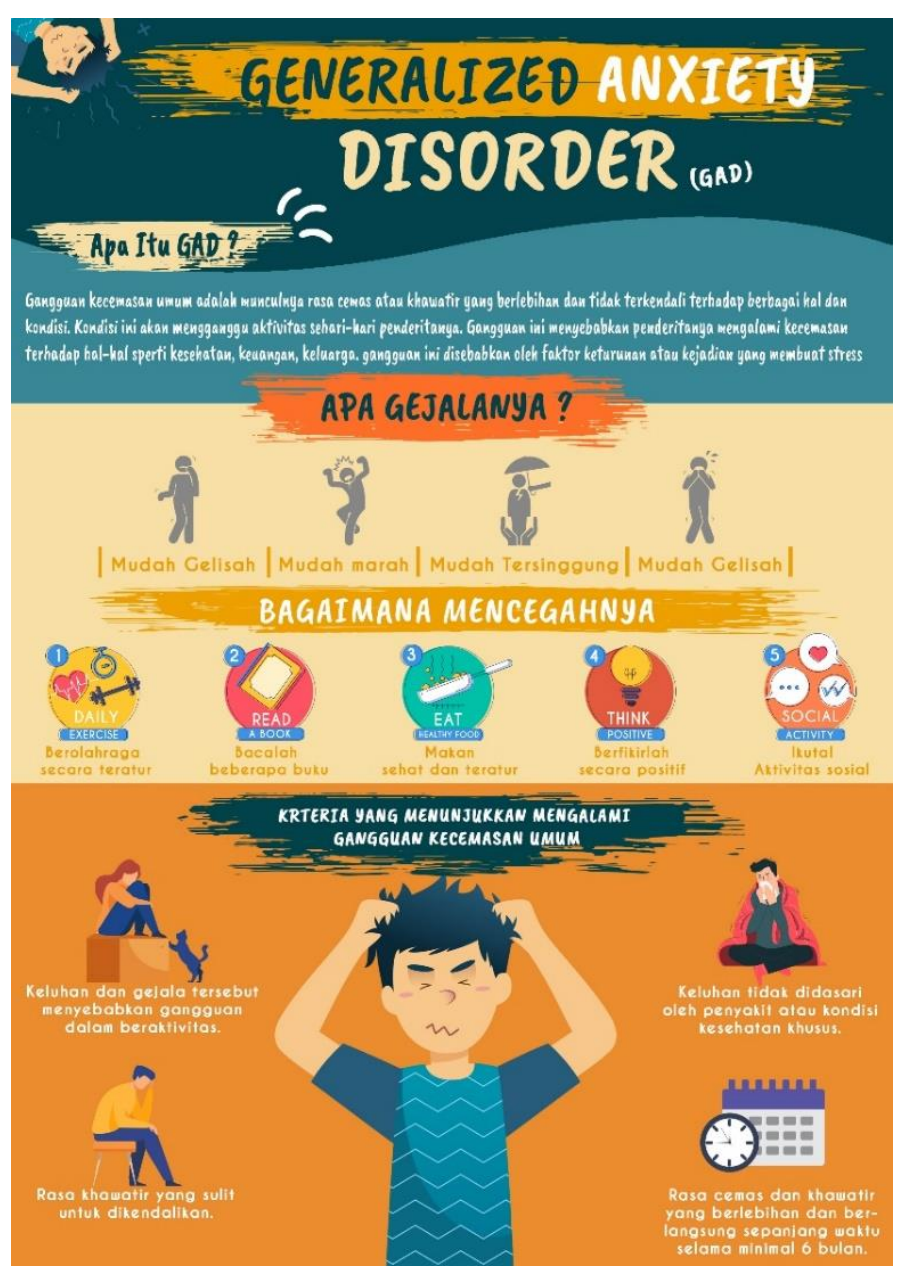

Gamabar 3. Infografis General Anxiety Disorder Sumber: Dokumentasi pribadi, 2020

\section{SIMPULAN}

Banyak orang yang belum mengetahui tentang penyakit gangguan kecemasan dan hanya mengannggapnya sebagai penyakit biasa. Pada kenyataannya itu merupakan penyakit yang dapat mengganggu produktivitas dan fungsi seseorang pada kehidupannya. Banyak dari mereka tidak mengetahui gejala ataupun tindakan prefentif untuk mencegah bagaimana gangguan kecemasan bisa terjadi. Salah satu gangguan yang paling sering muncul adalah GENARALIZED ANXIETY DISORDER (GAD) atau Gangguan Cemas Menyeluruh. Gangguan cemas bisa berlangsung sangat lama, bahkan seumur hidup. Oleh karean itu, peneliti membuat solusi dengan memberikan informasi menggunakan infografis statis. Infografis ini menggunakan elemen visual yang harmoni untuk menghasilkan komposisi yang dapat membuat pembaca rileks dan mendapat informasi yang cukup. Poster yang peneliti buat di sini menggunakan gaya visual flat design agar lebih mudah mengilustrasikan informasi yang dituju. Warna yang dipilih juga memperhatikan 
dari sisi psikologis untuk lebih menarik perhatian pembaca. Huruf yang dipilih juga menggunakan jenis keluarga sans serif agar lebih mudah untuk dibaca dengan ukuran yang besar. Sebagai media informatif, infografis statis ini dibuat dengan tampilan mudah dan sederhana, namun juga memperhatikan kepadatan informasi yang dimuat agar pesan tersampaikan dengan baik ke khalayak.

\section{DAFTAR PUSTAKA}

Annisa, D. F., \& Ifdil, I. (2016). Konsep Kecemasan (Anxiety) pada Lanjut Usia (Lansia). Konselor, 5(2), 93. https://doi.org/10.24036/02016526480-0-00

Asrori, A. (2015). Terapi Kognitif Perilaku Untuk Mengatasi Gangguan Kecemasan Sosial. Jurnal Ilmiah Psikologi Terapan (JIPT), 03(Vol 3, No 1 (2015)), 89-107. http://ejournal.umm.ac.id/index.php/jipt/article/view/2128

Chou, Y., Agus, D., \& Juliawati, D. J. (2017). Perbedaan Proporsi Gangguan Depresi dan Gangguan Cemas Antara Mahasiswa Preklinik dan Klinik. 6(3), 146-152. https://doi.org/10.22146/jpki.32234

Diferiansyah, O., Septa, T., Lisiswanti, R., Kedokteran, F., \& Lampung, U. (2016). Gangguan Cemas Menyeluruh Rumah Sakit Jiwa Provinsi Lampung. Jurnal Medula Unila, 5(2), 63-68.

Evans, S., Ferrando, S., Findler, M., Stowell, C., Smart, C., \& Haglin, D. (2008). Mindfulnessbased cognitive therapy for generalized anxiety disorder. Journal of Anxiety Disorders, 22(4), 716-721. https://doi.org/10.1016/j.janxdis.2007.07.005

Humaida, R., Ningsih, C., Kurniawati, E., \& Komarudin, U. (2016). Diagnosis dan Terapi pada Pasien Gangguan Ansietas Menyeluruh Pria usia 60 tahun Diagnosis and Therapy for General Anxiety Disorders of 60 Years Old Male Patient. 6, 149-154.

Maba, A. P. (2017). Paradoxical intervention dalam bimbingan dan konseling untuk mengatasi kecemasan. Counsellia: Jurnal Bimbingan Dan Konseling, 7(2), 99. https://doi.org/10.25273/counsellia.v7i2.1852

Nesia, R. T., Kurniawati, F., Psikologi, F., Indonesia, U., Cina, P., Beji, K., \& Depok, K. (2020). Keterlibatan Orang Tua Dalam Intervensi Parental Involvement in Anxiety Disorder Intervention. 4(1), 30-35.

Prabowo, P. S., \& Sihombing, J. P. T. (2010). Gambaran gangguan kecemasan pada mahasiswa Fakultas Kedokteran Universitas "X" angkatan 2007. Jkm, 9(2), 161-168.

Pratama, A. P., Widyorini, E., \& Hastuti, L. W. (2012). Penerapan cogntive-behavioral therapy untuk menurunkan gejala-gejala generalized anxiety disorder pada remaja. PrediksiKajian Ilmiah Psikologi, 1(2), 229-233.

Tobergte, D. R., \& Curtis, S. (2013). Kecemasan. Journal of Chemical Information and Modeling, 53(9), 1689-1699. https://doi.org/10.1017/CBO9781107415324.004

Vildayanti, H., Puspitasari, I. M., \& Sinuraya, R. K. (2018). Farmakoterapi Gangguan Anxietas. Farmaka, 16(1), 196-213. https://doi.org/10.24198/JF.V16I1.17446

Soewignjo, S. (2013). Seni Mengatur Komposisi Warna Digital. Yogyakata: Taka Publisher. 